\title{
The Impact of the Implementation of Organizational Excellence Policies on the Contextual Performance: A Case Study in the Cardiovascular Surgery Hospital
}

\author{
Omar Durrah $^{1}$, Naser Khdour ${ }^{1} \&$ Samir Al-Abbadi $^{1}$ \\ ${ }^{1}$ Business Administration Department, Philadelphia University, Jordan \\ Correspondence: Naser Khdour, Business Administration Department, Philadelphia University, Jordan. E-mail: \\ nkhdour@philadelphia.edu.jo
}

Received: May 25, 2014

Accepted: June 18, 2014

Online Published: August 25, 2014

doi:10.5539/ibr.v7n9p17

URL: http://dx.doi.org/10.5539/ibr.v7n9p17

\begin{abstract}
This research aims to identify the concept of excellence, its organizational requirements and various models, as well as to identify organizational citizenship behaviors and levels of organizational commitment among sample hospital staff. Furthermore, it aims to study the impact of organizational excellence policies on the dimensions of contextual performance. The research has been applied on a sample of 76 members of both majors (doctors, nurses) working at the heart surgery hospital in the city of Aleppo, Syria. The following conclusions have been reached: Employees moderately exercise policies of both organizational excellence (empowerment, training, wages and incentives) and contextual performance dimensions (organizational citizenship, organizational commitment). Moreover, there was an observed positive correlation with one of the policies of organizational excellence (empowerment) on the dimensions of contextual performance, while there was no observed significant effect of both policies (training, wages and incentives) on the dimensions of contextual performance.
\end{abstract}

Keywords: organizational excellence policies, contextual performance, empowerment, organizational citizenship, commitment, cardiovascular surgery hospital

\section{Introduction}

Syria has witnessed several changes at the beginning of the third millennium, accompanied by educational and medical changes and developments in the health sector, together with a series of challenges affecting the performance of the health sector. One of the most prominent challenges is the increase of the intensity of competition in providing medical services inside and outside Syria. This obliged hospitals to unify all of its employee's efforts so as to improve its services in order to ensure its continuous existence, and to achieve excellence among competitors.

Health organizational awareness and its role to improve quality in the market-place as well as customer satisfaction, increases with the rises of concerns in industrial services inciting hospitals' employees to perform more than their official duties and responsibilities, in order to achieve the minimum level of performance.

Modern hospitals have begun working to create a spirit of initiative and innovation, giving their workers the freedom to act within certain limits, and consider that this kind of behavior affects the performance that individuals willingly exert in hospitals, It has been found that the official functional requirements for an individual in hospitals is no longer enough to achieve excellence. Therefore, there should be voluntary activities exercised by the individual, in addition to the official activities, to develop the individual's performance and to face future variable and permanent challenges.

\section{Research Problem}

Medical improvements currently being witnessed by the world encourage all societies to use all the available administrative methods and modern technologies to develop medical services and to provide strategies and derive the modern system that enables society to keep pace with the progress. It is the responsibility of the hospitals at such a time of information revolution, to overcome the contemporary challenges which face human recourses and to distinguish it in providing medical services. Thus, the research problem can be summarized by the location of the organizational excellence policies' impact on the contextual performance, and recognizing 
what kinds of impacts and changes these policies have on the hospital workers. This can be explored through answering the following questions:

How available are the organizational excellence policies? (Empowerment, training, wages and motivations) in the same hospital? And is it possible for this hospital to be a distinguished hospital with such current policies?

What is the situation of the organizational citizenship behaviors and the level of organizational commitment in the same hospital?

What is the impact of each policy of organizational excellence (empowerment, training, wages and motivations) on each scope of the contextual performance (organizational citizenship, organizational commitment) for the workers in the same hospital?

\section{Research Objectives}

Providing a scientific framework about the concept of organizational excellence and its requirements and forms; and clarifying the concept of the contextual performance and its different dimensions.

Studying the common organizational excellence policies in the hospital (empowerment, training, wages and motivations) and its effect on the contextual performance dimensions (organizational citizenship, organizational commitment).

Providing a set of recommendations and proposals to the hospital to avoid the shortcomings in the performance of these policies and to encourage them to exercise organizational citizenship behavior and organizational commitment in order to upgrade the level of the efficiency and effectiveness of the work in the hospital.

\section{The Research Significance}

The scientific aspect as it deals with two important variables at the social and humanitarian studies level, which are organizational excellence and contextual performance. Both of these are considered to be relatively modern concepts in the Arab World. Highlighting the importance of the role of human resources in the practice of organizational citizenship behavior and strengthening organizational commitments through the appropriate climate to reach the organizational excellence for hospitals. The scientific addendum which may arise from this research could also be of importance and could enhance the Library with a case study which may attract further researchers' attention because of its scarcity in the health sector. In addition to the practical aspect which arises from studies which work in the scope of the human resources rationalization and by taking these policies from the organizational excellence concepts, and comparing them with the prevailing applied situation. It also highlights the need to apply the concept of organizational excellence and the contextual performance in Syrian environment, especially in the health sector and to draw attention to the importance of hospitals as organizations, based on knowledge and learning that have a complex and a private nature.

\section{Research Model and Variables}

- Independent Variables: Organizational excellence policies (empowerment, training, salaries and motivations).

- Dependent Variables: contextual performance dimensions (organizational citizenship, organizational commitment).

- Demographic Variables: (gender, age, academic qualification, and experience).

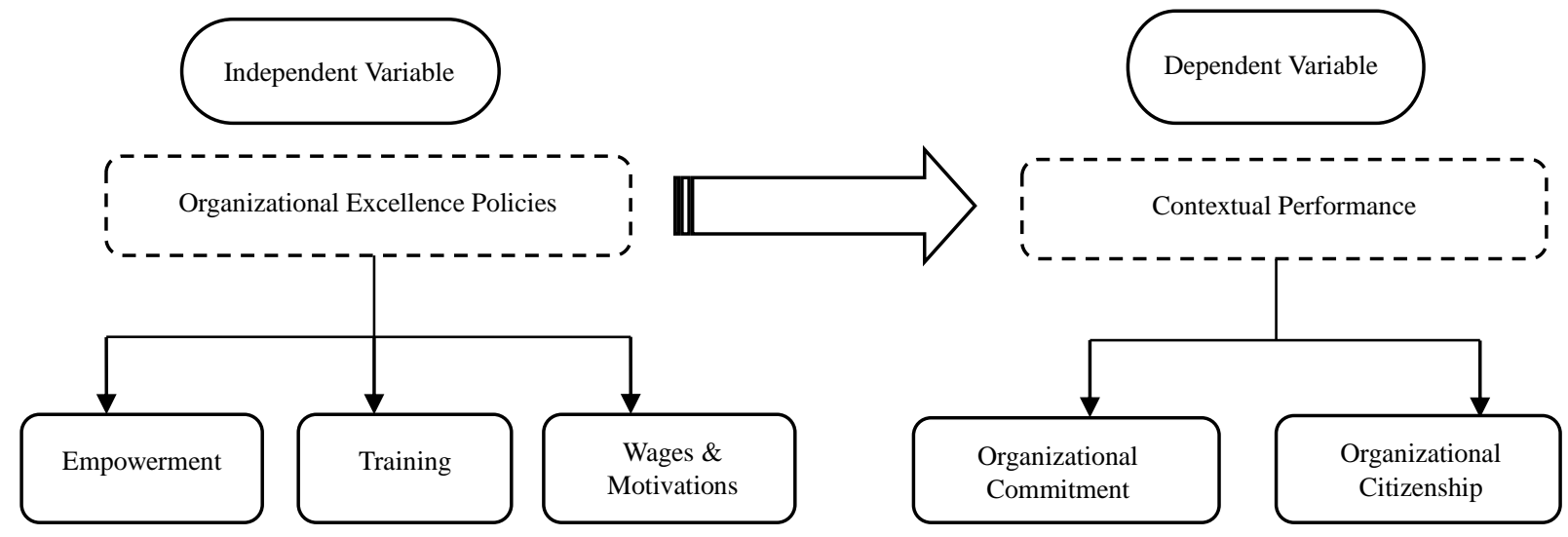

Figure 1. Research model 


\section{Research Hypotheses}

Organizational excellence policies (empowerment, training, wages and motivations) don't morally affect the contextual performance dimensions (organizational citizenship, organizational commitment) and are divided to the below sub-hypotheses:

Organizational excellence policies (empowerment, training, salaries and motivations) don't morally affect the organizational citizenship.

Organizational excellence policies (empowerment, training, salaries and motivations) don't morally affect the organizational commitment.

\section{Research Methodology}

This study depends on the analytical descriptive approach, and this approach is based on combining desk and field research. The desk study aims to collect the relevant scientific material through reviewing Arabic and foreign books and references, periodicals, bulletins, articles, conferences and reports, theses (Ph.D., Master) and the Internet. Whilst the field study aims to examine hypotheses through a questionnaire addressed to the workers in the Cardiovascular Surgery Hospital in Aleppo, through collecting data through the questionnaire and then uploading and analyzing the data.

\section{Research Sample}

The research community consists of one hospital (case study) which is the Cardiovascular Surgery Hospital in Aleppo. Table 1 shows the number of employees in each specialty. The researchers applied this study only to two categories, doctors and nurses as they serve the research purposes better than other disciplines:

Table 1 . Research community

\begin{tabular}{ccccccc}
\hline Hospital & \multicolumn{3}{c}{ Number of employees } & & Total \\
\hline & Doctors & Management & Nursing & Technical & Others & \\
Heart Surgery & 42 & 23 & 53 & 46 & 52 & 216 \\
\hline
\end{tabular}

The researchers distributed 95 questionnaires to all the doctors and nurses in the hospital. 76 were recovered, of which $80 \%$ were valid for statistical analysis, 10 were rejected and 9 were lost, as detailed in Table 2 below:

Table 2. Distributing the sample on disciplines

\begin{tabular}{lccc}
\hline \multirow{2}{*}{ Hospital } & \multicolumn{3}{c}{ Number of forms for the disciplines } \\
\cline { 2 - 4 } & Doctors & Nursing & Sum \\
\hline Heart Surgery & 35 & 41 & 76 \\
\hline
\end{tabular}

\section{Questionnaire Format}

The required data has been collected by a special tool (questionnaires) especially written for this purpose, after consideration of the theoretical aspect along with previous studies, bearing in mind that it covers the study variables by using Likert Fivefold Criteria, and distributing it in the study case which consists of doctors and nursing staff in the Cardiovascular Surgery Hospital in Aleppo. This questionnaire consists of 3 sections:

1) Demographic variables: comprises of 5 variables (gender, age, academic qualifications, experience, job), and all of them have been measured through direct questioning.

2) Independent variables: including the organizational excellence policies which have been measured through 27 sentences where the terms were relevant to 3 policies of organizational excellence.

a) Empowerment: this dimension has been measured in 12 sentences;

b) Training: this dimension has been measured in 9 sentences;

c) Wages and Motivation: this dimension has been measured in 6 sentences.

3) Dependent variables: including the Contextual performance dimensions which has been measured through 18 terms linked with two dimensions of the contextual performance.

a) The organizational citizenship: this scope has been measured in 9 sentences. 
b) The organizational commitment: this scope has been measured in 9 sentences.

\section{Statistical Analysis Methods}

The data has been analyzed and the validity of the hypotheses has been tested based on a set of statistical methods by using (SPSS. V. 17). Program, the used methods is listed as follows:

Cronbach's Alpha variable;

Distributing the sample's terms based on the repetition and percentages;

Descriptive statistics (mean \& the standard deviation);

Multiple Regression analysis.

\section{Research Borders}

The research has been applied in the Cardiovascular Surgery Hospital in Aleppo - only.

The research sample covers only the doctors and nursing staff in the Cardiovascular Surgery Hospital in Aleppo, and the results of this research concerns these workers in the hospital only and has no relation to other hospitals.

The research uses only three policies of the organizational excellence (Empowerment, Training, Wages and Motivation).

The research uses only two dimensions of the contextual performance (Organizational citizenship, Organizational commitment).

The confidence level of $95 \%$ has been used in testing the validity of assumptions and generalizing results. The researchers have personally distributed the Questionnaires to the members of staff during the period of 1/6/2012 to $1 / 7 / 2012$.

\section{Research Terms}

1) Organizational excellence: reaching the highest level of excellence which makes the organization suitable and competitive at a global level (Sharma and Kodali, 2008).

2) Contextual Performance: the activities contribute in the organization's effectiveness in a several ways, working on the formation of psychological and social context of the Organization, which is considered as a catalyst for the Organization's activities and operations (Organ, et. al., 2006).

3) Organizational citizenship: is a group of voluntary behaviors performed willingly by the individual and not as a part of their official work and raises the organizational effectiveness (Robbins, 2001).

4) Organizational commitment: is the individual's willingness and readiness to provide all of their capacity and enhance their loyalty, and to put forward the maximum effort they can give for the benefit of their organization (Gardner, et. al., 2007).

\section{Previous Studies}

- $\quad$ Study - Armitage, et al., 2005: The study aimed to provide an overview of the philosophy and methodology of the seven foundations to enable the leaders to achieve distinguished results in their organizations. The study identified the seven organizational excellence pillars which were: strategy, customers, operations, individuals, relations, learning, and alignment.

- Study - Sharma and Talwar, 2007: The study aimed to explore various models of excellence in order to reach one model that included all points in these forms then to build a model called 'comprehensive organizational excellence model' which consisted of a set of the elements of leadership, strategic planning, the values of individuals, common values, value of the customers, and those of business results.

- Study-Angela, 2008: The study aimed to determine the importance of the behaviors of additional roles associated with the organizational performance and evaluating behavior levels. The study observed that there were no substantial differences in the staffing trends towards organizational citizenship behaviors' variables, according to differences in work grades and academic qualifications and monthly salaries, and there were substantial differences in the trends in staffing towards variables of organizational citizenship behavior regarding differences in age, marital status, gender and experience.

- Study - Han, et al., 2009: The study aimed to identify the levels of the organizational commitment, career satisfaction and empowerment of nurses in some hospitals in South Korea comparing between temporary and permanent nurses, the study showed that permanent nurses have higher level of the organizational commitment and empowerment compared to permanent nurses. 
- $\quad$ Study - Chang, et al., 2010: The study aimed to identify organizational commitment levels for the nursing elements, and recognizing the role of empowerment in the enhancement of job satisfaction, and in improving levels of organizational commitment. The study focused on the impact of empowerment as a mediating variable in the relationship between job satisfaction and organizational commitment. The result has showed that the organizational commitment level for the nursing elements is above the medium grade. The empowerment has an important role and a positive impact on the job satisfaction and the organizational commitment.

\section{The Theoretical Part}

Even though there is a considerable body of literature concerning Business Excellence, the large majority of it is anecdotal and based on stories of various areas of success from a range of different individuals. It has been generally considered that this particular area is one in which there is an identifiable need for a theoretical basis which could offer a format on which various possible empirical studies were able to be based.

\subsection{Organizational Excellence Concept}

The vast scientific and technological development in the business environment lead to increasing competition between organizations, which drives the organization to look for organizational and managerial practices that can help them achieve excellence, leading to prosperity and growth in the business world.

The organizational excellence is considered one of the modern management concepts and one of the most important objectives of business organizations, as it indicates the ability to provide services to others in an innovative form that is distinguished from other competitors. (Elkhaldi, 2012).

Excellence is found to determine the ability of organizations to achieve superior quality and performance (Mostahfezian, et al., 2012).

Therefore, the researchers can define organizational excellence as a dynamic process that seeks to improve the performance of the Organization and increase the level of quality of goods and services.

Organizational excellence requires the presence of all ameliorative activities in the organization and these calls for the provision of a set of requirements or basis, which are: strategies, customers, processes, people, learning, relationships and alignment (Porter, and Steven Tanner, 2004).

It is possible to measure the performance of an organization by the use of the Model of Excellence EFQM's framework for self-assessment or by the MBNQA Model (Zairi, 2005). It is possible to gain some concept of the value and effect of an organization's quality management by performing constant measurements on the management results and subjecting the findings to quality experts. Indeed the measuring of the success of a company's management is of constant importance especially in the current competitive market and that there has been observed a difference between how the majority of employees view the management performance and how the leaders plan their strategies for the company (Curkovic, et. al., 2000). It is necessary for companies to discover some form of connection between the realities of the business and the performance metrics by identifying the actions of the employees which fundamentally affect the goals of the company and to establish metrics in order to assess the employees. By the use of the Baldrige Criteria which can be discovered in the MBNQA (2007) described by the leadership category, it is possible to achieve an optimum performance (Blazey, 2006). There is, in the MBNAQ (2007), a focus on the measures used to investigate senior leaders' performance and it has been observed (Blades, 1995) that it comprises of a framework for organizations to assess their performance. Over the years it has been utilized due to the criteria changing so as to name companies and organizations which can be identified as demonstrating levels of excellence in their performance.

The true benefit of this award of quality is the actual act of measuring the improvement of a company and many companies and organizations have been observed (Zairi, 2005) to make use of the criteria as proposed by the MBNQA in order to self-assess their progress in the area of general improvement and also by considering their potential for further improvement whilst also competing for the award. The provision of a measure in the form of a comprehensive framework, for any business wishing to understand further its potential further has been suggested to be one of the main reasons that the MBNQA has been so well established (Curkovic, et. al., 2000). By considering certain particular relationships with a specified quantity of criteria, by taking areas of businesses or organizations partially or completely, the attempt to validate empirically such examples of award quality models have been attempted in a few studies. However, the large proportion of these works (Flynn and Saladin, 2006; Curovic, et. al., 2000; Black \& Porter, 1996) there has been a particular focus on the model of the MBNQA, despite the fact that there have been a few exceptions (Nabitz, et. al., 2001). It is necessary to engage in further studies of a similar nature, and to utilize similar methods in the collection of the data and its analysis, so as to accumulate further definitive indicators as to the validity of such models; as we consider that the lack of 
firm theoretical foundations tend to form a significant disadvantage to these frameworks, and is one which presents considerable difficulties to the research itself.

The actual concept of the idea of quality has been described as being that of excellence (Campbell \& Rozsnyai, 2002). This is a modern concept and one in which the improvements and control approaches form processes which are strategic and can be employed as tools for qualitative and quantitative evidence. When instrumental action occurs due to assumed control, the resultant observations can be open to question (Bound, et. al., 1994), in that it is more applicable to complex, competitive environments (Hill \& Jones, 1998) cited in (Singh, 2004) together with a requirement for Quality (Karami, 2007). There are closer relations between the control and the implementation of the formulated strategy, in this particular approach. With regards to the modern control approach, two separate levels have been identified (Dess, et. al., 2007) as that of 1) the control of information and that of 2) the control of behavior.

1) The control of information is primarily focused on the environment, both internal and external and examines these environments in order to create a strategy to consider if the business or organization will be able to discover relevant strategies and goals by its current course of action.

2) The control of behavior focuses on the both the formulation and the actual implementation of the particular strategy identified by the business or organization. The examination of the business or organization and the enquiry into how it is progressing, requires careful consideration of both the culture and its reward system, in order to establish boundaries necessary for the implementation of control of behavior. This control of behavior is considered to be necessary for a business or organization to compete in any given environment and is implicit in any contract which is to be long term.

This modern system of control needs to satisfy a certain number of criteria so as to be effective and fulfill its roles as a key method of gathering and examining basic continuous data. In order for the TM to perform a strategy of serious action, the approach needs to be continually tightly focused on information regarding changes in the working environment. Lower and Middle Management need to be supplied with important information so as to give regular, frequent attention to such data. The collection of the information and data via the system of control need to be examined through one-to-one interviews. Any of the outcomes of the use of the mechanism of governance need to align the interests of the shareholders and the strategic system of control (Dess, et. al., 2007; Mintzberg, 2008). They also need to ensure that the performance and activities of the business or organization are both well established and are properly maintained in order to obtain the required quality (Karami, 2007).

There are certain benefits arising from good governance's modern approach which are that the Board of Directors are more involved and are committed; the shareholders are more active in the organization or business and there is a system of incentives and rewards for effective managers (Mintzberg, 2008). Three main characteristics have been identified as indicators of sound quality models (Blades, 1995), which consist of a) Simplicity - the model needs to be able to be easily understood, remembered and straightforward to use;

b) Graphic - the model needs to be able to be pictorially represented due to the observation that pictures tend to be more easily remembered, especially when used for purposes of education;

c) Meaningful - the model needs to give a true meaning for the concepts which are used throughout the structure.

In a recent study combing observations of critical factors apparent in awards arising from the Deming Prize, there was found to be a positive correlation between the various criteria given for each individual award of quality (Kangi, 2002). The earlier observation that when assessed using comparative weightings of criteria for excellence across various countries, for example by using Deming, MBNQA, and EFQM, leaders, enablers, certain specific strategies and policies, processes and individuals all appeared to obtain the highest weightings in EFQM. This was as opposed to those observed in Deming and MBNQA. The highest results were observed in the MBNQA apart from those for society (Kirke, 1999).

This particular research considers the critical factors appertaining to well-known awards for excellence which have become apparent due to the Deming Prize together with nine criteria of the tool for self-assessment-RADAR. It also considers approaches to quality which will be further described and examined in various following awards (Miguel, 2001). Various positive correlations have been observed (Kangi, 2002) throughout the criteria for the different awards for quality. Each of the different requirements were assessed as to their importance by the use of R:5 as a maximum measure and R:1 as a minimum measure of the highest and lowest correlations respectively together with using the second column to describe the different levels of importance of the weighting by timing the amount. 
It was observed that organizational strategies had various performance assessments build into them by the setting of objectives and by the linkage of standards of excellence. By the provision of strategic choice for the customer together with the diligent assessment of performance with regards to the provision of value that forms the basis of its particular policy, mission and vision (Zairi, 1999).

\subsection{International Forms for Organizational Excellence}

Japan Quality Award: is an award established in Japan in 1951 by the Union of Japanese Scientists and Engineers and has been associated with the scientist Edward Deming. This prize is granted to: firstly individuals, especially those who have made research and applied contributions in the field of quality or quality research and publishing; and secondly to organizations aiming to encourage them to develop their practices in the area of statistical control of quality (Tito, 1993).

The American Malcolm Baldrige National Quality Award (MBNQ): is an Award established by the American Congress in 1987 to increase awareness of quality management and to reward American companies that succeed in the implementation of quality management systems. Two awards can be granted annually in each of the three categories-industrial companies, service companies, and small projects. The American Model is based on a set of main concepts that reflect the values of excellence and effectiveness, which primarily stem from the total quality management model and thinking process (Lee \& Quazi, 2001).

The European Foundation for Quality Management Award (EFQM): is an award established in 1991 by the European Organization for Quality Management and is granted annually to organizations that achieve quality and continuous improvement in products and services, and for companies and production units, public sector institutions and medium or small institutions. This award consists of two sets: the first is Enablers-the base to support performance and enable the organization to achieve excellence. The second is Results-which are aimed results that lead to distinguished work results (Taey \& Kodada, 2008).

Dubai Government Excellence Program: is a means to encourage continuous development and improvement for the level of services provided for customers by the local departments of Dubai Government, offering an annual opportunity to honor department's administrators, work groups, initiatives, distinguished projects, and distinguished employees (Dubai Excellence Award, 2001).

King Abdallah the Second's Award for Excellence: in Jordan King Abdullah II's Center for Excellence was established in 2006 to manage this award. The Center is considered the National Reference for quality and excellence in all sectors. Its role is the dissemination of the culture of excellence. The Center presents an award called 'King Abdullah II's Award for Excellence' to any ministry, official/non-official institution, Company or individual in accordance to the principles, criteria and fields adopted by the Board of Trustees of the center (Ebdallah, 2009).

\subsection{Organizational Excellence Policies}

Empowerment: Is granting authorities and responsibilities to workers and giving them confidence, freedom of action, decision-making and participation in the organizations' management and solving the problems they face. It is a means of encouraging them to take a step in order to face the recurring situations which offer them autonomy to work out of the cycle of routine performance (Nava, et.al. 2008).

Training: The training of human resources is one of the most important elements that could lead an organization to worldwide levels of performance. Almost none of models of Excellence are devoid from the training component. This process is very important in order to achieve quality, so it must be carried out periodically and impartially, depending on the source of internal and external evaluation of training (Lee and Croker, 2006)

Wages and Motives: The wage and incentives policy is one of the most important policies whose role is retaining qualified human resources and creating motivation for all individuals who can support the organization in its efforts to achieve its goals for which it exists (Abdallah, 2009).

\subsection{Contextual Performance}

Is the behavior that supports the psychological and social environment of the organization, contributing to the organization's culture and climate and the way activities are implemented (Van Scotter, 2000).

\subsection{Contextual Performance Dimensions}

Organizational Citizenship: The concept of the organizational citizenship is considered a main pillar in building human, behavioral and organizational relations inside and outside the organization. This concept reflects the organization's ability in their environmental and social interactions, and their support for consensus values in order to raise the efficiency and effectiveness of the organizational performance level where-ever this concept 
skips the official excuses of behavior and includes important supportive data for the official organizational behavior for the additional roles (Elfahdawi, 2005). Organizational citizenship behavior is known as an optional voluntary behavior aimed to enhance the performance of the organization and enhance its effectiveness and efficiency (Febles, 2005).

Organizational Commitment: Organizational commitment is one of the human objectives organizations seek to achieve through linking organization and its workers due to the effective impact it has on the stability of the human resource continued performance. It is known as the psychological state which links the individual with the organization to achieve its objects, and adopt its values (Carlson, 2009). The organizational commitment is considered one of the most important topics in the study of organization because of its important effects on behaviors and trends of individuals, and its reflections on the individual and the organization, equally. It is considered as an important factor in ensuring the success of organizations, their continuation and increasing the quality of its services (Durrah, 2011).

\section{Statistical Analysis}

\subsection{Test the Validity and Reliability of Standards}

The questionnaire has been endorsed by arbitration where it has been well formulated and based on different points of view of previous researchers, and presented to experienced arbitrators. The stability of the questionnaire has been verified by using an internal gradient consistency Alfa Cronbach (Cronbach's), and for the standard to have a stable scale the minimum value of the parameter in this test it should not be less than 0.70 .

The results in Table 3 show that the value of the Alpha Cronbach ranged between 0.701 and 0.891 . These values are considered high, accordingly, it can be stated that all standards in the research are featured with internal stability for their terms.

Table 3. Alfa Cronbach's factors for study variables

\begin{tabular}{lcc}
\hline Variable & Alfa Cronbach's Factor & No. of terms \\
\hline Empowerment & .834 & 12 \\
Training & .758 & 9 \\
Wages and incentives & .745 & 6 \\
Organizational excellence & .818 & 27 \\
Organizational Citizenship & .763 & 9 \\
Organizational Commitment & .701 & 9 \\
Contextual performance & .847 & 18 \\
All study's variables & .891 & 45 \\
\hline
\end{tabular}

\subsection{Describing the Sample's Features}

Table 4. Distributing the sample terms according to demographic variables

\begin{tabular}{llll}
\hline Demographic Variables & Categories & Frequency & Percentage \% \\
\hline \multirow{2}{*}{ Gender } & Male & 37 & 48.7 \\
Marital Status & Female & 39 & 51.3 \\
& Single & 33 & 43.4 \\
& Married & 43 & 56.6 \\
Age & Less than 30 & 31 & 40.8 \\
& 30- less than 40 & 20 & 26.3 \\
& 40- less than 50 & 14 & 18.4 \\
& More than 50 & 11 & 14.5 \\
Years Of Experiences & Less than two years & 14 & 18.4 \\
& 2-5 & 29 & 38.2 \\
Job & 5-10 & 20 & 26.3 \\
Total & More than 10 & 13 & 17.1 \\
\hline
\end{tabular}




\subsection{Descriptive Statistics for Research Variables}

Table 5. Mean and standard deviations for the search variables

\begin{tabular}{llccc}
\hline Variable & Variable's Dimensions & No. of Terms & Mean & Standard Deviation \\
\hline \multirow{2}{*}{ Organizational Excellence Policies } & Empowerment & 1 to 12 & 3.46 & .611 \\
& Training & 13 to 21 & 3.01 & .567 \\
Total measures for the Organizational Excellence Policies & Wages \&Motives & 22 to 27 & 2.50 & .631 \\
& & 1 to 27 & 3.10 & .414 \\
Contextual Performance Policies & Organizational Citizenship & 28 to 36 & 3.50 & .599 \\
Total Measures for the Contextual Performance & Organizational Commitment & 37 to 45 & 3.21 & .585 \\
\hline
\end{tabular}

From Table 5 the following is shown:

The workers in the Cardiovascular Surgery Hospital practice the empowerment policy more than the average, where the mean of this policy is 3.46 with a standard deviation of 0.611 may be due to the fact that the management of this hospital grants workers some authority and independence in the implementation of their work, especially doctors. The training policy on average has the mean of 3.01 and the standard deviation of 0.567 which may be due to the lack of sufficient interest in the management of this hospital in training courses for workers, especially nurses. Additionally to the weak budget for training programs, there was not a clear display of awareness of wages and incentive policies. Here the mean was 2.50 and the standard deviation was 0.631 which could have been due to the lack of consent of the majority of workers in this hospital on the wages and incentives system used especially that it was a government hospital that worked within specific controls and regulations.

In general, the workers in the Cardiovascular Surgery Hospital practiced the organizational excellence policies in a moderate way, where the mean of these policies combined were 3.10 and the standard deviation was 0.414 and it also showed that the most used organizational excellence policies in the hospital was the policy of empowerment, training policy, and finally the wages and incentives policy.

The workers in the Cardiovascular Surgery Hospital exercised the organizational citizenship behaviors more than the average, where the mean for these behaviors was 3.50 and the standard deviation was 0.599 which was due to the fact that some doctors and nurses did additional functions outside working hours, as well as the cooperation and assistance among colleagues in case of huge workloads. It appeared that the levels of organizational commitment in the hospital had increased to be more than the average, where the mean was 3.21 and the standard deviation 0.585 which may have been due to emotional attachment and psychological satisfaction between staff and the hospital.

In general, the Cardiovascular Surgery Hospital Workers' exercise the contextual performance dimensions in a degree that was above average, where the mean of these policies combined was 3.35 and the standard deviation 0.552 also showed that the most used among contextual performance dimensions was the organizational citizenship behaviors, then the organizational commitment levels.

\subsection{Hypothesis Test}

The First Hypothesis Test: The organizational excellence policies (empowerment, training, wages and incentives) were not found to morally affect the organizational citizenship. So the researchers have used multiple regression analysis to test this hypothesis.

Table 6. The multiple regression form for the organizational excellence policies in the organizational citizenship

\begin{tabular}{|c|c|c|c|c|c|c|}
\hline \multirow{2}{*}{$\begin{array}{l}\text { Policies of Organizational } \\
\text { Excellence }\end{array}$} & \multicolumn{2}{|c|}{ Unstandardized Coefficients } & \multirow{2}{*}{$\frac{\text { Standardized Coefficients }}{\text { Beta }}$} & \multirow{2}{*}{$\mathrm{t}$} & \multirow{2}{*}{ Sig. } & \multirow{2}{*}{$\begin{array}{l}\text { Statistical } \\
\text { Significance }\end{array}$} \\
\hline & B & Std. Error & & & & \\
\hline Empowerment & .610 & .098 & .623 & 6.245 & .000 & Morale (Sig) \\
\hline Training & .048 & .094 & .046 & .514 & .609 & Non-moral \\
\hline Wages and Motives & .123 & .097 & .130 & 1.273 & .207 & Non-moral \\
\hline Constant & .936 & .412 & & 2.272 & .026 & \\
\hline
\end{tabular}




$\begin{array}{ll}\text { Form's Indicators } & \\ (\mathrm{F})=22.66 & (\mathrm{R} 2)=.486 \\ (\mathrm{Sig} .)=.000 & (\text { Adjusted R })=.464 \\ (\mathrm{R})=.697 & (\text { Std. Error Estimate })=.438\end{array}$

Table 6 shows the following:

The validity of the form used to test the affecting relationship between organizational citizenship and organizational excellence policies, where the value of $\mathrm{F} 22.66$ with a moral standard of 0.000 is less than 0.05 which means that this model with its independent variable is able to be used to predict the value of the dependent variable.

The correlation between independent variables and the dependent variable is equal to 0.697 which means that the relationship between the organizational excellence and the organizational citizenship policies has a direct correlation and strength of this relationship $69.7 \%$ and is considered a good force to some extent.

There is one policy of the organizational excellence policies that affects positively on the organizational citizenship which is: Empowerment, while the remaining two policies do not affect morale on the organizational citizenship: training, wages and incentives.

The determination linear $\mathrm{R} 2=0.486$ which means that the independent variables for the organizational excellence policies (empowerment) explains about $48.6 \%$ of the change in the dependent variable (organizational citizenship) and is a moderate proportion, and that the $51.4 \%$ were due to other variables have not been subject of the study, or due to an accident.

According to the multiple regression results: the first assumption will be partially rejected relevant to any moral effect for the organizational excellence policies (empowerment) in the organizational citizenship, while the first assumption will be partially accepted relevant to moral effect for organizational excellence policies (training , wages and motives) in the organizational citizenship.

The Second Hypothesis Test: The organizational excellence policies (empowerment, training, wages and incentives) were not found to affect morally in the organizational commitment.

So the researchers have used multiple regression analysis to test this hypothesis:

Table 7. The multiple regression form for the organizational excellence policies in the organizational citizenship

\begin{tabular}{|c|c|c|c|c|c|c|}
\hline \multirow{2}{*}{$\begin{array}{l}\text { Policies of Organizational } \\
\text { Excellence }\end{array}$} & \multicolumn{2}{|c|}{ Unstandardized Coefficients } & \multirow{2}{*}{$\frac{\text { Standardized Coefficients }}{\text { Beta }}$} & \multirow{2}{*}{$\mathrm{t}$} & \multirow{2}{*}{ Sig } & \multirow{2}{*}{$\begin{array}{l}\text { Statistical } \\
\text { Significance }\end{array}$} \\
\hline & B & Std. Error & & & & \\
\hline Empowerment & .646 & .090 & .675 & 7.141 & .000 & Morale \\
\hline Training & -.124 & .087 & -.120 & -1.423 & .159 & Non-moral \\
\hline Wages and Motives & .075 & .090 & .081 & .839 & .404 & Non-moral \\
\hline Constant & 1.158 & .381 & & 3.035 & .003 & \\
\hline
\end{tabular}

Form's Indicators

$\begin{array}{ll}(\mathrm{F})=27.94 & (\mathrm{R} 2)=.538 \\ (\text { Sig. })=.000 & (\text { Adjusted } \mathrm{R})=.519 \\ (\mathrm{R})=.733 & (\text { Std. Error Estimate })=.406\end{array}$

Table 7 shows the following:

The validity of the form used to test the affecting relationship between organizational citizenship and organizational excellence policies, where the value of $\mathrm{F}=27.94$ with a moral standard of 0.000 is less than 0.05 which means that this form with its independent variable is valid to be used to predict the value of the dependent variable.

The correlation between independent variables and the dependent variable is equal to 0.733 which means that the relationship between the organizational excellence policies and the organizational citizenship has a direct 
correlation and the strength of this relationship is $73.3 \%$ and is considered a good force.

There is one policy of the organizational excellence policies that affects positively on the organizational citizenship which is: empowerment, while remaining two policies do not affect morale on the organizational citizenship: training, wages and incentives.

The determination linear R2 $=0.538$ which means that the independent variables for the organizational excellence policies (empowerment) explain about $53.8 \%$ of the change in the dependent variable (organizational citizenship) and it is a moderate proportion, and $46.2 \%$ were due to other variables not been the subject of the study, or due to an accident.

According to the multiple regression results: the first assumption will be partially rejected relevant to any moral effect for the organizational excellence policies (empowerment) in the organizational commitment, while the first assumption will be partially accepted relevant to moral effect for organizational excellence policies (training, wages and motives) in the organizational commitment.

\section{Results}

The degree of practicing the organizational excellence policies (empowerment, training, and wages and motives) in the Cardiovascular Surgery Hospital in Aleppo was found to be within the medium range.

The most used among organizational excellence policies by the workers was empowerment then training policy and lastly wages and motives policy.

The degree of practicing the contextual performance scoops (organizational citizenship, organizational commitment) in the Cardiovascular Surgery Hospital in Aleppo was found to be a little bit above the medium scale.

Workers in this hospital practice organizational citizenship behaviors was found to be close to a good degree, while their organizational commitment was to some extent above the medium range.

The empowerment policy as one of the organizational excellence policies affected positively on the two contextual performance scoops (organizational citizenship and organizational commitment).

There was no observed moral effect of the two organizational excellence policies (training and wages and motives) on the organizational performance organizational citizenship and organizational commitment).

\section{Recommendations}

The hospital management should pay attention to the organizational excellence policies and should work on developing them by:

Enabling employees in the hospital, especially doctors and nurses by giving them more authority and the freedom to take action so as to implement their work and to find appropriate solutions to problems facing them, providing them an opportunity to participate in decision-making, particularly those related to their work.

Focusing on training and allocate sufficient funds to identify training needs on a regular basis and to let workers, especially doctors to have many of the training courses, whether internal or external, designing training programs that focuses on the social aspects and the capacity to adapt with the nature of the work in hospitals with continuous evaluation of the training process on a regular basis.

Create a wages and motives system based on the objective criteria linked with performance and achievement, as well as the excellence motives that must be included in this system.

Hospital's management team should continue to work on promoting the spirit of the organizational citizenship in worker's lives by creating an organizational climate or culture in order to help workers to adopt such behaviors by providing more opportunities for career development and progress in the future, and linking rewards and incentives with the level of high organizational citizenship showed by workers.

Enhancing the organizational commitment levels of the staff of the hospital through career development, motives, rewards, good treatment, and respect from the management; to pay more attention to staff members; to provide appropriate guidance together with opening a line of communication with them; to create a spirit of sincerity, dedication and loyalty to the hospital at which they work.

The researchers recommend studying the following research areas in the future:

A study on the effect of organizational excellence policies on the career satisfaction.

A study on the impact of the application of international excellence standards for the medical quality services in hospitals. 
A study on the relationship between the contextual performance and the functional performance.

\section{References}

Angela, L. (2008). Organizational Citizenship Behavior in Professional Service Industry Sales Personnel. PHD, Capella University.

Armitage, J., Brooks, N., \& Carlen, M. (2005). The 7 Essentials of Business Excellence (pp. 1-25), White Paper.

Black, S. A., \& Porter, L. J. (1996). Identification of the Critical Factors of TQM. Decision Sciences, 27(1), 1-21. http://dx.doi.org/10.1111/j.1540-5915.1996.tb00841.x

Blades, M. (1995). Development of a Simple Model for Analysis of Quality. Training of Quality, 3(1), 9-13. http://dx.doi.org/10.1108/09684879510082201

Blazey, M. L. (2006). Insights to Performance Excellence, 2006: An Inside Look at the 2006 Baldridge Award Criteria. Milwaukee, Wis: ASQC Quality Press.

Bounds, G., Yorks, L., Adams, M., \& Ranney, G. (1994). Beyond Total Quality Management: Towards the Emerging Paradigm. New York: McGraw-Hill International Editions.

Campbell, C., \& Rozsnyai, C. (2002). Quality Assurance and the Development of Course Programmers: Papers on Higher Education. Regional University Network on Governance and Management of Higher Education in South East Europe UNESCO, CEPES: Bucharest.

Carlson, D. (2009). Self-Efficacy and Employee Satisfaction in Cross Utilization Teams: Predicting Organizational Commitment and Turnover Intention of Cross Utilization Employees. Ph.D., Capella University.

Curkovic, S., \& Landeros, R. (2000). An Environmental Baldrige. Mid-American Journal of Business, 15(2), 63 76. http://dx.doi.org/10.1108/19355181200000012

Dess, L., \& Alan, E. (2007). Strategic management creating competitive advantages. New York: McGraw- Hill Irwin.

Dubai Excellence Award. (2001). Assessment Elements Handbook (p. 10). Dubai.

Durrah, O. (2011). Continuous Learning Strategies And Their Impact On Organizational Commitment Applied To Aleppo Government Hospitals (p. 92). PhD, Faculty Of Economics, Aleppo University.

Ebdallah, O. (2009). The Impact of Implementing International Standards in Human Resources on the Customers Recognition of the Quality of Healthcare Services (p. 137). PhD, Commerce Faculty, Ain Shams University.

Elfahdawi, F. (2005). The Relationship Between Organizational Citizenship And Transformational Change a Field Study Regarding The Perspectives Of Government Employees In Karak City. Management Sciences Studies, 32(2), 368-392.

Elkhaldi, S. (2012). The Role Of Quality Of Service And The Abilities Of Organizational Learning In Developing The Excellence Culture A Field Study In Industrial Companies Listed In Kuwait Financial Stock Market (p. 126). Masters Degree Theses, Business Faculty, Middle East University.

Febles, M. (2005). The Role of Task and Contextual Performance In Appraisal Fairness and Satisfaction (p. 28). $\mathrm{PhD}$, Faculty of the California School of Organizational Studies, Alliant International University.

Flynn, B. B., \& Saladin, B. (2006). Relevance of Baldrige Constructs in an International Context: A Study of National Culture. Journal of Operations Management, 24(5), 583-603. http://dx.doi.org/10.1016/j.jom.2005.09.002

Gardner, T., Moynihan, L., \& Wright, P. (2007). The Influence of Human Resource Practices and Collective Affective Organizational Commitment on Aggregate Voluntary Turnover. Center of Advanced Human Resource Studies, Cornell University, Ithaca, NY.

Kangi, G. K. (2002). Measuring Business Excellence: Routledge Advances in Management and Business Studies (pp. 36-68). Taylor and Francis Group.

Karami, A. (2007). Strategy Formulation in Entrepreneurial Firms. Ashgate Publishing.

Li-Chun, C., Chia-Hui, S., \& Shu-Man, L. (2010). The Mediating Role of Psychological Empowerment on Job Satisfaction and Organizational Commitment for School Health Nurses: a Cross-Sectional Questionnaire Survey. International Journal of Nursing Studies, 47(4), 67-93.

Li-Yueh, L., \& Croker, R. (2006). A Contingency Model to Promote The Effectiveness of Expatriate Training. 
Industrial Management \& Data Systems, 106(8), 1187-1205. http://dx.doi.org/10.1108/02635570610710827

Miguel, P. (2001). Comparing the Brazilian National Quality Award with Some of the Major Prizes. TQM Magazine, 13(4), 260-272. http://dx.doi.org/10.1108/09544780110391675

Mintzberg, H. (2008). How productivity killed American enterprise. Retrieved from http//www.mintzberg.org

Mostahfezian, M., et al. (2012). Organizational Intelligence and Excellence Based on EFQM Model among the Isfahan Sport Boardsare Interrelated. World Journal of Sport Sciences, 6(4), 301-329.

Nabitz, U., et al. (2001). Improving the EFQM Model: An Empirical Study on Model Development and Theory Building Using Concept Mapping. Total Quality Management \& Business Excellence, 12(1), 69-81. http://dx.doi.org/10.1080/09544120020010101

Nava, A., Dean, K., \& Wesley, Y. (2008). Female Empowerment: Impact Of A Commitment Savings Product in The Philippines. Journal of Human Resources, 1-26.

Organ, D., Podsakoff, P., \& Mackenzie, S. (n. d). Organizational Citizenship Behavior: Its Nature, Antecedents, and Consequences. Vikalpa, 32(1), 16.

Porter, L., \& Tanner, S. (2004). Assessing Business Excellence (2nd ed., p. 15), Elsevier Butterworth-Heinemann.

Porter, L., \& Tanner, S. J. (1998). Accessing Business Excellence. Oxford: Butterworth-Heinemann.

Pui-Mun, L., \& Quazi, H. (2001). Methodology for Developing a Self Assessment Tool to Measure Quality Performance in Organizations. International Journal of Quality \& Reliability Management, 18(2), 25-45.

Robbins, S. (2001). Organizational Behavior (p. 312). Prentice-Hall, Upper Saddle River, Nj.

Sang-Sook, H., Sook, M., \& Eun, Y. (2009). Empowerment, Job Satisfaction, and Organizational Commitment: Comparison of Permanent and Temporary Nurses in Korea. Applied Nursing Research, 22(4), 1-19.

Sharma, A., \& Talwar, B. (2007). Evolution of Universal Business Excellence Model Incorporating Vedic Philosophy. Measuring Business Excellence, 11(3), 4-20. http://dx.doi.org/10.1108/13683040710820719

Sharma, M., \& Kodali, R. (2008). Development of a Framework for Manufacturing Excellence. Measuring Business Excellence, 12(4), 50-66. http://dx.doi.org/10.1108/13683040810919962

Singh, S. P. (2004). Corporate strategy. India: A.I.T.B.S Publishers and Distributors.

Taey, R., \& Kodada, I. (2008). Total Quality Management (p. 367). Amman, Alyazordy.

Tito, C. (1993). Bulding Total Quality (p. 281). Chaoman and Hall, London.

Van S. J. (2000). Relationship of Task Performance nda Contextual Performance With Turnover, Job Satisfaction, and Affective Commitment. Human Resource Management Review, 10(1), 55-80.

Zairi, M. (1999). Managing Excellence: Policy and Strategy. TQM Magazine, 11(2), 74-79. http://dx.doi.org/10.1108/09544789910260367

Zairi, M. (2005). TQM Sustainability: How to Maintain Its Gains through Transformational Change. School of Management, University of Bradford.

\section{Copyrights}

Copyright for this article is retained by the author(s), with first publication rights granted to the journal.

This is an open-access article distributed under the terms and conditions of the Creative Commons Attribution license (http://creativecommons.org/licenses/by/3.0/). 